\title{
Steven R. Gullberg, Astronomy of the Inca Empire: Use and Significance of the Sun and the Night Sky
}

\author{
Cham, Switzerland: Springer, 2020. Hardback, 370 pp., 42 b/w illus., 275 \\ colour illus. ISBN 978-3-030-48365. €135.19.
}

\section{Brian S. Bauer \\ University of Illinois at Chicago \\ Bsb@uic.edu}

"We need to return to the basics". That is the advice that I would offer Steven R. Gullberg on his newly published book, Astronomy of the Inca Empire: Use and Significance of the Sun and the Night Sky. The basics of "horizon astronomy", such as was used by the Inca (ca. AD 1400-1572), include the fact that from almost any point on earth where one can see the western or eastern horizon, one can witness solar events, such as the Sun rising or setting (including on the solstices). Another basic fact is that the more horizon measurements researchers take from any given location, the more likely it is that they will find some kind of correlation with a solar event; and once that correlation is identified, it becomes easy to disregard all the negative results. Here, I am reminded of the fact that, while there are more than 800 straight Nazca lines, only a few lines point to solstice positions on the horizon. Yet, in most publications, we are only shown those few solstice-oriented lines, and not the many hundreds that point in other directions. This logic, of finding what one is looking for and losing sight of the rest, also works for astronomical observations made from archaeological ruins. In the case of ruins which offer a view of the horizon, if one records enough measurements from different locales, positions and angles, one will eventually record some sort of an "alignment" with a solar event. One is then tempted to ignore the hundreds of misses and concentrate on the few hits and elevate their importance. The relative ease of finding so-called "astronomical alignments" from archaeological sites is especially misleading when one starts a project with the belief that such alignments exist and it is only a matter of taking enough measurements to find them.

In the case of The Astronomy of the Inca Empire, the author begins with the wellestablished thesis that the Incas followed the Sun's movements across the horizon and marked especially important days in the year, such as the June and December solstices, with large public ceremonies. These astronomical events were observed from a few very 
specific locations, and several early Spanish writers note that the Incas built towers on the horizon to help them mark the solstices precisely. The field research for this book becomes questionable, however, when the author begins taking large numbers of measurements from a range of 31 sites, both large and small, in the Cusco region, searching for possible observation points. The results become even more questionable when he does not require the presence of constructed horizon markers to confirm a "solar alignment". The constructed horizon markers by the Inca were not only unambiguous landmarks, but they substantiated a precise observation of solar events that were spatially constrained that is, a measurement like the solstice can be made with those markers only at a specific time from a very specific place. Abandoning the need for these observational aids opens a much more ambiguous set of claims: that people could see the Sun set or rise in a general area roughly at the time of the solstice. It seems that for Gullberg, if you can see a special sunrise or sunset from a location, that alone is evidence enough to call it an "astronomical" location.

Unfortunately for the author, just because one can observe an event on the horizon (such as a solstice) from a location, this does not mean that that locale was an observatory point. As noted above, you can generally see the horizon (as well as the Sun setting and rising) from most places on earth, and if one takes enough measurements - from doorways, windows, niches, hallways, rocks and terrace walls - at any site, there is a good chance that one of those measurements will align with a known horizon event. In this way, archaeo-astronomy becomes archaeo-wishful thinking and, more importantly, it degrades the skills of the ancient sky watchers by assuming a lack of precision that would never be acceptable in modern astronomical practice.

In The Astronomy of the Inca Empire, Gullberg combines the well-established knowledge that the Incas did watch and mark the movements of the Sun on the horizon with his own visits to a large number of Inca sites to search for additional evidence of Inca astronomy. Engaging in an Easter-egg-like hunt through an eclectic set of ruins of the Cusco region, Gullberg stops to take measurements at numerous sites and, not surprisingly, he finds many so-called alignments. The reader learns, for example, that at the site of Rumiwasi Bajo, a rock and building complex in the Valley of Cusco, "[o]ne doorway to the passageway [...] looks out in the general direction of June solstice sunset but is $12^{\circ}$ off" (p. 183); that at the nearby site of Kusicallanca, one of the walls of the largest buildings "is oriented such that the December solstice Sun will rise behind it" (p. 184); and that at the carved rock called Titikaka near the town of Chinchero a "cave will receive light at the time of, but is not perfectly aligned for, the December solstice sunset" (p. 216). Exemplifying an "if you take enough measurements and visit enough sites you will find something" enthusiasm, Gullberg writes of the site Kusilluchayoc that "several masonry walls form multiple rooms with windows and niches on Kusilluchayoc's western face. Both a corridor between the rocks and a body-size niche face the setting point of the June solstice Sun" (p. 158).

To these observations and dozens of others that are presented in the book, I would return to perhaps the most basic element of scientific research, "correlation does not imply causation". For example, on a trip to our nation's capital, a visitor from Peru might discover 
that the Washington Monument casts a shadow, and that as such, it could have been used as a giant gnomon. The visitor might even include of picture of themselves pointing to the shadow, and looking at their watch, on the June solstice as proof of the observation. But that observation would not provide any useful information to understand the role that astronomy played in American culture during the nineteenth century and we would hope that the visitor (or reader) would not pay much heed to it. In short, observations need to be placed in cultural context.

I suggest that the real challenge of archaeoastronomy is not simply finding places from where one can see important events on the horizon - these are all around us, especially when one is willing to accept "not perfectly aligned" as good enough - but in documenting and explicating why very specific locations were selected to be used by past people to make those observations, and if possible, what cultural events accompanied those observations. When archaeoastronomy is reduced to a list of possible places where people could/might have watched an event, little new knowledge is produced. Yet, it seems for Gullberg that anytime one can see a solstice on the horizon from a ruin - no matter how far away, or "off", or imperfectly aligned - that observation becomes evidence of a culturally important sightline. So, it is not unexpected that he reports finding dozens of sightlines from different sites in the Cusco region. In fact, it seems that if you take enough measurements most Inca sites offer views of solar events on the horizon - this is not an astonishing fact in a mountain environment. Whether or not those specific sightlines were meaningful to the Inca is not explored in detail, or confirmed by other means, such as pairs of stone pillars, which we know were in use during Inca times. The simple existence of a sightline provides support for the author's assumption that they all must have held importance and are noteworthy.

The Astronomy of the Inca Empire is written in a clear, clean English and it includes a series of excellent photographs of many poorly documented Inca sites in the Cusco region. Nevertheless, there is little evidence of a true mastery of the Spanish chroniclers, as no new information from these writers is presented nor are they discussed in any meaningful detail. The overall value of the book is also lessened by the uncritical inclusion of some of the bizarre claims popularised by Cusco's tourist guides, such as references to the nonsensical "pyramid of Ollantaytambo" (p. 246 and 247). Among these completely unsubstantiated "theories", Gullberg presents his own, by explaining that a mirror's reflection can be seen in the site of Llactapata from Machu Picchu on the June Solstice sunrise (something I suspect would be visible on most any other sunrise of the year as well, a detail that the author fails to consider in his search for specific alignments). Gullberg speculates that this mirror-reflection could have been part of some elaborate solstice ceremony held by the Inca, but then abruptly changes direction, admitting that "there is no evidence in the chronicles that this type of ceremony took place". The only clear case of a solstice observation location outside of the city of Cusco that the book documents is that of the Urubamba pillars as seen from the Qespiwanka rock in the town of Urubamba, an astronomical alignment that was suggested as early as 1995 and was first securely documented in 2003 in a publication by Carlos Ayme Carrasco, Mereida Puma Soria and Octavio Fernández Carrasco that goes unmentioned by the author (Ayme Carrasco et al. 2003). The book also offers 
no help to future scholars as Gullberg attempts to resuscitate many of the baseless and baroquely adorned theories of R. T. Zuidema concerning Inca astronomy - most of which have been shown to be devoid of merit. In summary, anyone paying the eye-popping price of nearly $\$ 160$ asked by the publisher may well be disappointed.

\section{References}

Ayme Carrasco, C., M. Puma Soria and O. Fernández Carrasco, 2003. "Pacha Unancha: Astronomía Inka en Urubamba". Revista Saqsaywaman 6: 217-279. 